\title{
Nutritive properties of aqueous extract Justicia carnea leaves and its effects on haematological and some biochemical indices of anaemia induced male wistar albino rats.
}

\author{
Orjiakor Chidiogo Anthonia1, Uroko Robert Ikechukwu ${ }^{2 *}$, Njoku Obioma Uzoma1, Ezeanyika \\ Lawrence Uchenna Sunday ${ }^{1}$ \\ ${ }^{1}$ Department of Biochemistry, University of Nigeria, Nsukka, Nigeria \\ ${ }^{2}$ Department of Biochemistry, College of Natural Sciences, Michael Okpara University of Agriculture, Umudike, Abia \\ State, Nigeria
}

\begin{abstract}
This study investigated nutritive properties of aqueous extract of $J$. carnea leaves and its effects on haematological and biochemical indices of anaemia induced male Wistar albino rats. In the nutritional study, proximate composition, phytochemicals, antinutritonal factors, minerals and vitamins analyses were carried out using standard analytical procedures. Eighteen male Wistar albino mice were used for the acute toxicity study while 28 male Wistar albino rats were used for haematological and biochemical study. The rats were randomly distributed into seven groups of four rats each with group 1 as normal control. Group 2 was anaemia induced untreated, and group 3 was anaemia induced treated with 50 $\mathrm{mg} / \mathrm{kg} \mathrm{b}$. wt. of Astyfer. Groups 4-6 were anaemia induced and treated with 100,300 and $500 \mathrm{mg} / \mathrm{kg} \mathrm{b}$. wt. of the extract respectively. Group 7 was non-anaemic rats that received $500 \mathrm{mg} / \mathrm{kg} \mathrm{b}$. wt. of the aqueous extract. Nutritional study showed richness of the aqueous extract in proximate composition, phytochemicals, minerals and vitamins contents. The extract caused no adverse reactions or death in the animals indicating it is relatively safe for consumption. Significant $(\mathbf{p}<\mathbf{0 . 0 5})$ reduction in the levels of haematological indices observed in anaemic rats were significantly $(p<0.05)$ reverted within 4 to $8 \mathrm{~d}$ of treatment with the extract when compared with group 2 . There were no significant difference observed in the liver marker enzymes activities and renal function indices concentrations of all the anaemic rats treated with the aqueous extract when compared with normal control, which could be attributed to the aqueous extract lacking potentials of causing liver and renal damage. These findings suggest that aqueous of $J$. carnea leaves is safe, nutritionally rich with no toxic effects on liver and kidney function indices, and possesses anti-anaemic effects due to its blood boosting and replenishing properties.
\end{abstract}

Keywords: Anaemia, Nutrition, Haematology, Liver marker enzymes, Kidney function indices.

Accepted on May 15, 2018

\section{Introduction}

Anaemia is a widespread public health problem associated with an increased risk of morbidity and mortality, especially in pregnant women and young children [1]. Among, nutritional (such as vitamin and mineral deficiencies) and non-nutritional (such as infection and haemoglobinopathies) factors that contribute to onset of anaemia, iron deficiency and malaria play an important role. Others include; inherited genetic defects, medication-related side effects, and chronic disease [1]. Anaemia is frequently caused by loss of Red Blood Cells (RBCs), reduction in the production of $\mathrm{RBCs}$, increased destruction of RBCs, and shorter life span of RBCs [2]. We now understand that persistent bleeding episodes, deficiency of vitamins like cobalamin and folic acid, hyper-splenism, autoimmune haemolysis, renal dysfunction, and radio- chemotherapeutic intervention could aggravate anaemic condition [3].

Anaemia as haematological defect affects people of all ages resulting in marked reduction of Red Blood Cells Counts (RBCs) and circulating haemoglobin concentration below required amounts needed to meet physiological needs [4]. Reduction of haemoglobin is usually accompanied by a fall in red blood cell count and Packed Cell Volume (PCV) but these amounts may be normal in some patients with subnormal haemoglobin level [5]. Non-nutritional anaemia (such as sickle-cell anaemia and thalassaemia, which are induced by genetic disorders) is suffered most by people in Sub-Saharan Africa, but these are few in comparison to the number of people with nutritional anaemia [5]. Incidence of anaemia is more common in underdeveloped countries because of poor 
nutrition and the presence of parasites that extract blood from the intestines [6].

Many edible plants possess numerous health benefits outside normal nutritional properties commonly attributed to their nutraceutical properties [7]. A good number of medicinal plants have been traditionally employed in alleviating anaemic condition. Some of these plants include; Telfeira occidentalis, Combretum dolichopetalum, Psorospermum ferbrifugum, Jatropha curcas, Flacourtia flavenscens and Brillantasia nitens and Justicia carnea [8,9]. Local consumers of J. carnea leaves mostly anaemic patients and pregnant women claim that $J$. carnea leaves possess blood boosting properties more effective than above listed medicinal plants and well known Western blood tonics though this is no sufficient scientific data to back up their claims.

Justicia carnea belongs to the family of Acanthaceae consisting about 600 species of herbs, shrubs and tender perennial native to the tropics and subtropics [10]. Its' common name in Brazil and South America include: Brazilian plume, flamingo flower, Jacobinia, pine-bur begonia, pink jacobinia, pink tongues, king's crown and cardinal's guard [11]. Justicia carnea is generally considered as an ornamental plant [12]. Several species of Justicia are widely used in folk medicine for the treatment of inflammation, respiratory, and gastrointestinal disorder [10]. Most of the medicinal properties exhibited by plant extracts such as antimicrobial, antioxidant, hypocholesterolemic and anti-cancerous are associated with their bioactive constituents mainly phenols and flavonoids [13]. It has also been reported to be rich in both macronutrients and trace elements of which calcium and iron are in high quantity [14]. Justicia carnea is used as blood tonic locally in many parts of Nigeria and there is no sufficient scientific evidence to support its use as blood tonic by traditional consumers. This study investigated nutritive properties of aqueous extract $J$. carnea leaves and its effects on haematological and some biochemical indices of anaemia induced male Wistar albino rats.

\section{Materials and Methods}

\section{Plant material}

Justicia carnea leaves used in this study were collected from Ozalla Isuofia in Anambra State and identified by Mr. Ozioko Alfred of Bioresource Development and Conservation Programme (BDCP) Research Centre, Nsukka.

\section{Animals}

Twenty-eight male Wistar albino rats were used for the haematological studies and biochemical studies while 18 male albino mice were used for the acute toxicity $\left(\mathrm{LD}_{50}\right)$ study. All the animals used were obtained from the Animal House of the Faculty of Biological Sciences, University of Nigeria, Nsukka. The rats were acclimatised for $7 \mathrm{~d}$ under $12 \mathrm{~h}$ dark/light cycle, fed standard grower feed, and allowed free access to drinking water ad libitum.

\section{Chemicals and reagents}

The chemicals and reagents used were obtained from reputable companies and were of analytical grade, they include but no limited to the following:

\section{Methods}

Preparation and extraction of plant material: Justicia carnea leaves were handpicked and dried under shade for $7 \mathrm{~d}$ and milled to coarse powder using a hammer mill. Quantities, $400 \mathrm{~g}$ of ground $J$. carnea dry leaves were macerated with 1.5 $\mathrm{L}$ distilled for $24 \mathrm{~h}$ and filtered with Whatman no. 4 filter paper. The filtrate was concentrated to a semi-solid residue in a water bath at $60^{\circ} \mathrm{C}$, weighed and percentage yield calculated.

Proximate, phytochemicals, antinutritional factors, vitamins and minerals analyses of $J$. carnea leaves: Proximate compositions of $J$. carnea leaves were determined using the method of AOAC [15]. Phytochemical and antinutritional factors analyses of $J$. carnea leaves were carried out according to the methods of Harborne, and Trease and Evans [16,17]. Vitamins and mineral contents of $J$. carnea leaves were determined according to the methods of Pearson, and APHA respectively $[18,19]$.

\section{Experimental design}

Twenty-eight male Wistar albino rats were randomly distributed into seven groups of four rats each with group 1 as the normal control that received distilled water only. Group 2 rats served as positive control that was anaemia induced but not treated, group 3 served as standard control that was anaemia induced but treated with $50 \mathrm{mg} / \mathrm{kg} \mathrm{b}$. wt. of standard drug (Astyfer). Groups 4-6 were anaemia induced and treated with 100,300 and $500 \mathrm{mg} / \mathrm{kg} \mathrm{b}$. wt. of aqueous extract of $J$. carnea leaves respectively. Group 7 was non-anaemic rats that received $500 \mathrm{mg} / \mathrm{kg} \mathrm{b}$. wt. of aqueous extract of $J$. carnea leaves. The extract was administered to the rats orally with gavage tube every $24 \mathrm{~h}$ for $8 \mathrm{~d}$. Blood samples were collected before induction as baseline, immediately after induction, $\mathrm{d} 4$ and d 8 of treatment respectively for haematological study. Treatment of the rats with aqueous $J$. carnea leaves was continued for $14 \mathrm{~d}$ and blood samples collected on $\mathrm{d} 15$ for biochemical studies.

\section{Anaemia induction}

Anaemia was induced in the rats by the method of Stone [20]. This was performed by the withdrawal of $2 \mathrm{ml}$ of blood from each rat once in two days until they became anaemic after the $4^{\text {th }}$ day. Baseline haematological parameters were determined before and after the induction of anaemia.

\section{Acute toxicity test of aqueous extract of J. carnea leaves}

The method of Lorke was used for the acute toxicity test of the aqueous extract of $J$. carnea leaves [21]. 
Nutritive properties of aqueous extract Justicia carnea leaves and its effects on haematological and some biochemical indices of anaemia induced male wistar albino rats

\section{Determination of haematological parameters}

Haematological parameters: haemoglobin concentration $(\mathrm{Hb})$, Packed Cell Volume (PCV), White Blood Cell count (WBC) and Red Blood Cell (RBC) count were carried out according to the methods of Dacie and Lewis [22].

\section{Determination of alanine aminotransferase (ALT) activity}

Alanine aminotransferase activity was assayed according to the method described by Wroblewski and LaDue [23].

\section{Principle}

Alanine amino transferase activity is measured by monitoring the concentration of pyruvate hydrazone formed with 2, 4dinitrophenylhydrazine. The colour intensity is measured against the blank at $540 \mathrm{~nm}$.

\section{Determination of aspartate aminotransferase (AST) activity}

This assay was carried out according to the method described by the International Federation of Clinical Chemistry [24].

\section{Principle}

Aspartate aminotransferase activity is measured by monitoring the concentration of oxaloacetate hydrazone formed with 2, 4dinitrophenylhydrazine. The colour intensity is measured against the blank at $546 \mathrm{~nm}$.

\section{Determination of alkaline phosphatase (ALP) activity}

Alkaline phosphatase was determined according to the method described by International Federation of Clinical Chemistry [24].

\section{Principle}

The principle of this method is based on the reaction involving serum alkaline phosphatase and a colourless substrate of phenolphthalein monophosphate, giving rise to phosphoric acid and phenolphthalein, which at alkaline $\mathrm{pH}$ values, turns pink that can be determined spectrophotometrically.

\section{Determination of serum urea}

Serum urea concentration was determined according to the method of Varley and Alan [25].

\section{Principle}

The principle of this test is based on Urease-Berthelot method. Urea in serum is hydrolysed to ammonia in the presence of urease. The ammonia formed is then measured by Berthelot's reaction.

\section{Determination of serum creatinine}

Serum creatinine concentration was determined according to the method described by Peters [26].

\section{Principle}

The principle of this test is based on the reaction of creatinine in alkaline medium with picrate to form a coloured complex whose colour intensity is directly proportional to the creatinine concentration in serum at $520-546 \mathrm{~nm}$.

\section{Statistical analysis}

The results obtained were analysed using the Statistical Products and Service Solutions (IBM Statistics SPSS 20) and the results were presented as mean \pm standard deviation. Significant differences of the result were established by oneway Analysis of Variance (ANOVA) and the acceptable level of significance was $\mathrm{p}<0.05$ (95\% confidence level) [27].

\section{Results}

\section{Percentage yield of J. carnea leaves}

Extraction of $400 \mathrm{~g}$ of ground $J$. carnea leaves with $1.5 \mathrm{~L}$ of distilled water gave a percentage yield of $18.43 \%$ (73.72 g).

\section{Proximate constituents of aqueous extract of J. carnea leaves}

The proximate contents in Table 1 show that aqueous extract of $J$. carnea leaves contains high carbohydrate and protein contents. Moderate amount of ash and moisture contents were observed while fats and crude fibre contents were found to be low.

Table 1. Proximate composition of aqueous extract of J. carnea leaves.

\begin{tabular}{ll}
\hline Proximate parameter & Quantitative composition \\
\hline Moisture (\%) & $4.61 \pm 0.14$ \\
\hline Fats (\%) & $2.66 \pm 0.31$ \\
\hline Ash (\%) & $9.26 \pm 0.02$ \\
\hline Crude fibre (\%) & $3.68 \pm 0.23$ \\
\hline Protein (\%) & $26.71 \pm 0.02$ \\
\hline Carbohydrate (\%) & $53.07 \pm 0.07$ \\
\hline Each value is expressed as mean \pm standard deviation $(n=3)$
\end{tabular}

The data in Table 2 show that phenols and flavonoids were the dominant phytochemicals in the aqueous extract of $J$. carnea leaves having values of $9.19 \pm 0.15 \mathrm{mg} / \mathrm{g}$ and $7.06 \pm 0.05 \mathrm{mg} / \mathrm{g}$ respectively. Alkaloids, glycosides, reducing sugars and carbohydrates were present in moderate concentrations while 
saponin, tannins and terpenoids were present in low concentrations.

Table 2. Phytochemical constituents of aqueous extract of J. carnea leaves.

\begin{tabular}{lll}
\hline Phytochemicals & Qualitative screening & Bioavailability $(\mathbf{m g} / \mathbf{g})$ \\
\hline Alkaloids & ++ & $5.77 \pm 0.40$ \\
\hline Flavonoids & +++ & $7.06 \pm 0.05$ \\
\hline Glycosides & ++ & $5.39 \pm 0.49$ \\
\hline Carbohydrate & ++ & $4.10 \pm 0.09$ \\
\hline Saponins & + & $1.18 \pm 0.01$ \\
\hline Tannins & + & $0.70 \pm 0.00$ \\
\hline Reducing Sugar & ++ & $5.91 \pm 0.30$ \\
\hline Terpenoids & + & $0.30 \pm 0.04$ \\
\hline Phenols & +++ & $9.19 \pm 0.15$ \\
\hline
\end{tabular}

Key: +: Slightly present; ++: Moderately present; SD: Standard Deviation; Each value is expressed as mean \pm standard deviation $(n=3)$.

The data in Table 3 shows that aqueous extract of $J$. carnea leaves contain low levels of anti-nutrients such as phytate, trypsin inhibitor, oxalate, hydrogen cyanide and haemagglutinin.

Table 3. Anti-nutrient composition of the aqueous extract of J. carnea leaves.

\begin{tabular}{ll}
\hline Antinutritional factors & Quantities \\
\hline Phytate $(\mathrm{mg} / \mathrm{g})$ & $0.06 \pm 0.21$ \\
\hline Trypsin inhibitor $(\mathrm{TIU} / \mathrm{mg})$ & $0.06 \pm 0.00$ \\
\hline Oxalate $(\mathrm{mg} / \mathrm{g})$ & $0.06 \pm 0.04$ \\
\hline Hydrogen Cyanide $(\mathrm{mg} / \mathrm{g})$ & $0.07 \pm 0.00$ \\
\hline Haemagglutinin $(\mathrm{HIU} / \mathrm{mg})$ & $0.38 \pm 0.02$ \\
\hline Each value is expressed as mean \pm standard deviation $(\mathrm{n}=3)$
\end{tabular}

The mineral contents presented in Table 4 shows that the aqueous extract of $J$. carnea leaves was rich in minerals. It contained high concentration of calcium and iron while copper; magnesium and zinc were present in low concentration.

Table 4. Mineral constituents of aqueous extract of J. carnea leaves.

\begin{tabular}{ll}
\hline Mineral constituents & Quantities of minerals \\
\hline Iron $(\mu \mathrm{g} / \mathrm{g})$ & $8.61 \pm 0.38$ \\
\hline Copper $(\mathrm{mg} / \mathrm{g})$ & $0.03 \pm 0.00$ \\
\hline Zinc $(\mu \mathrm{g} / \mathrm{g})$ & $1.96 \pm 0.01$ \\
\hline Magnesium $(\%)$ & $1.06 \pm 0.01$ \\
\hline Calcium $(\%)$ & $4.59 \pm 0.00$ \\
\hline
\end{tabular}

Each value is expressed as mean \pm standard deviation $(n=3)$

The data in the Table 5 shows that aqueous extract of $J$. carnea leaves are rich in vitamins with vitamin $\mathrm{C}, \mathrm{B} 2$, and $\mathrm{B} 1$ as the major vitamin constituents. Vitamins B6 and B6 were the least available vitamins when compared with other vitamins present.

Table 5. Vitamin contents of aqueous extract of J. carnea leaves.

\begin{tabular}{ll}
\hline Vitamin constituents & Quantities \\
\hline Vitamin B1 $(\mathrm{mg} / \mathrm{g})$ & $1.37 \pm 0.40$ \\
\hline Vitamin B2 $(\mathrm{mg} / \mathrm{g})$ & $2.50 \pm 0.50$ \\
\hline Vitamin B6 $(\mathrm{mg} / \mathrm{g})$ & $0.04 \pm 0.00$ \\
\hline Vitamin B12 $(\mathrm{mg} / \mathrm{g})$ & $0.05 \pm 0.00$ \\
\hline Vitamin B9 $(\mathrm{mg} / \mathrm{g})$ & $0.77 \pm 0.03$ \\
\hline Vitamin A ( $\mu \mathrm{g} / \mathrm{g})$ & $2.97 \pm 0.05$ \\
\hline Vitamin C $(\mathrm{mg} / \mathrm{g})$ & $36.69 \pm 0.83$ \\
\hline Vitamin E $(\mathrm{mg} / \mathrm{g})$ & $0.30 \pm 0.00$ \\
\hline
\end{tabular}

Each value is expressed as mean \pm standard deviation $(n=3)$

The acute toxicity test of the aqueous extract $J$. carnea leaves in Table 6 shows that no deaths or adverse reactions occurred in the mice after $24 \mathrm{~h}$ of administration of the extract, even when $5000 \mathrm{mg} / \mathrm{kg} \mathrm{b}$. wt. of the extract was administered.

Table 6. Acute toxicity $\left(L D_{50}\right)$ of aqueous extract of J. carnea leaves.

\begin{tabular}{lll}
\hline & Dosage $\mathbf{( m g / k g}$ body weight) & Mortality \\
\hline Phase I & & \\
\hline Group 1 & 10 & $0 / 3$ \\
\hline Group 2 & 100 & $0 / 3$ \\
\hline Group 3 & 1000 & $0 / 3$ \\
\hline Phase II & & \\
\hline Group 1 & 1600 & $0 / 3$ \\
\hline Group 2 & 2900 & $0 / 3$ \\
\hline Group 3 & 5000 & $0 / 3$ \\
\hline
\end{tabular}

The data in Figure 1 shows mean percentage Packed Cell Volume (PCV) of normal and anaemia induced male Wistar albino rats treated with graded doses of aqueous extract of $J$. carnea leaves with group 5 rats having highest percentage PCV before anaemia induction (baseline). The anaemia induction caused significant decrease $(p<0.05)$ in PCV levels of groups' 2-6 rats when compared with the PCV levels observed in groups 1 and 7. Anaemia induced rats on $\mathrm{d} 4$ of treatment with graded doses of aqueous extract of $J$. carnea leaves showed increase in PCV levels though significantly lower when compared with PCV levels of groups 1 and 7. Group 3 anaemia induced rats treated with standard drug (Astyfer) and groups 4-6 anaemia induced rats treated with 
aqueous extract of $J$. carnea leaves showed significant $(\mathrm{p}<0.05)$ increase in PCV levels when compared with the group 2. PCV levels observed in-group 2 on $d 8$ was significantly $(\mathrm{p}<0.05)$ lower when compared with PCV levels recorded in groups 1 and 7. However, groups 3-6 showed no significant $(p>0.05)$ decrease in PCV levels on day 8 when compared with groups 1 and 7.

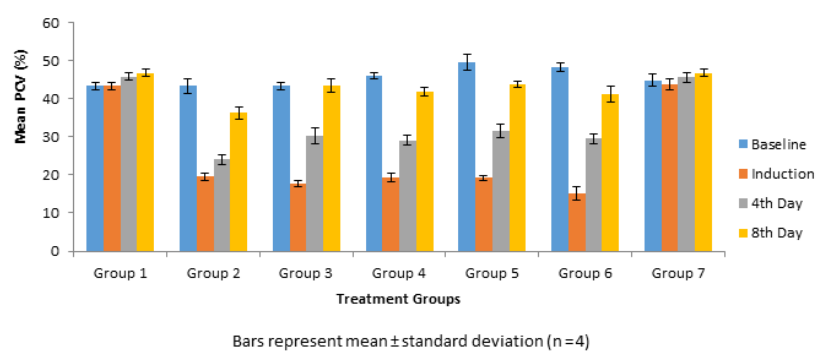

Figure 1. Effects of aqueous extract of J. carnea leaves on the Packed Cell Volume (PCV) of male Wistar albino rats before and after induction of anaemia.

Data in Figure 2 shows Red Blood Cell (RBC) counts normal and anaemia induced male Wistar albino rats, with all the rats having high RBC before anaemia induction (baseline RBC) administered graded doses of aqueous extract of $J$. carnea leaves. At baseline, groups 1, 3 and 6 had the higher RBC count amongst all the groups. Anaemia induction led to significant decrease $(\mathrm{p}<0.05)$ in $\mathrm{RBC}$ counts in groups 3-6 when compared with RBC counts of groups 1 and 7. After the fourth day of treatment with queous extract of $J$. carnea leaves, a significant decrease $(p<0.05)$ in $R B C$ count was observed in group 2 when compared to $\mathrm{RBC}$ count in group 1 . However, RBC countin all anaemia induced treated groups were significantly $(p<0.05)$ high when compared with group 2 , but were significant $(\mathrm{p}<0.05)$ lower when compared with $\mathrm{RBC}$ count of groups 1 and 7 after 4 days of treatment. After 8 days of treatment, no significant $(\mathrm{p}>0.05)$ increase in $\mathrm{RBC}$ counts was observed in group 7 while anaemia induced aqueous extract treated groups 3-6 showed no significant decrease in $\mathrm{RBC}$ counts when compared with the normal control (group 1).

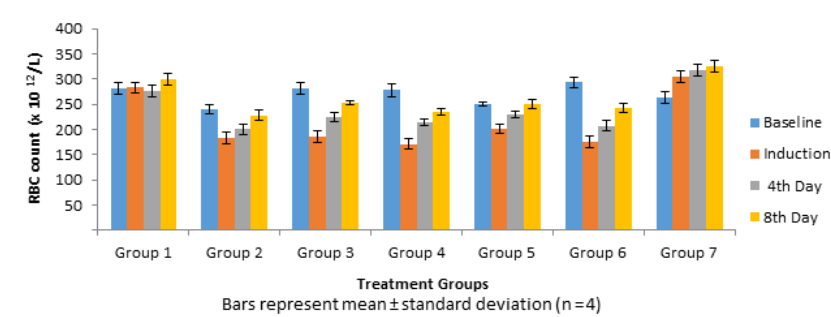

Figure 2. Effects of aqueous extract of J. carnea leaves on the Red Blood Cell (RBC) counts of male Wistar albino rats before and after induction of anaemia.

Haemoglobin concentrations of normal and anaemia induced male Wistar albino rats treated with graded doses of aqueous extract of $J$. carnea leaves indicated that all the rats had high baseline haemoglobin concentration (Figure 3). Induction of anaemia caused significant $(\mathrm{p}<0.05)$ decrease in haemoglobin concentrations in groups 2-6 when compared with group 1 when group 7 rats that were not anaemia induced. Treatment of the rats with aqueous extract of $J$. carnea leaves for $4 \mathrm{~d}$, resulted in significant $(\mathrm{p}<0.05)$ decrease in haemoglobin concentrations of all the anaemia induced rats (groups 2-6) while group 7 rats that was not anaemia induced showed no significant $(p<0.05)$ decrease in haemoglobin concentration when compared with group 1. Haemoglobin concentrations observed in groups 2-6 after 4 and 8 days of treatment were significantly $(p<0.05)$ higher than their corresponding haemoglobin concentrations after induction and 4 days of treatment respectively. After the $8^{\text {th }}$ day of treatment, significant $(p<0.05)$ decrease in haemoglobin concentration was observed in groups 2 while all extract treated anaemia induced rats (groups 4-6) no significant $(p>0.05)$ in haemoglobin concentrations when compared with group 1 . Haemoglobin concentration observed in group 3 anaemia induced rats after 8 days of treatment with standard was not significantly $(\mathrm{p}>0.05)$ lower when compared with group 1 .

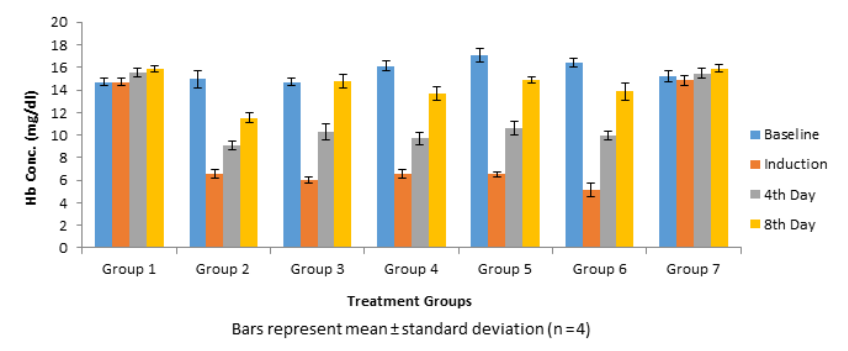

Figure 3. Effect of aqueous extract of $J$. carnea leaves on the haemoglobin concentration (Hb Conc.) of male Wistar albino rats before and after induction of anaemia.

White Blood Cell (WBC) counts of normal and anaemiainduced rats shown in Figure 4 indicated that all the rats had high WBC counts prior to anaemia induction. Anaemia induction led to significant $(\mathrm{p}<0.05)$ decrease WBC counts of groups 2-6 rats when compared with groups 1 and 7 rats that were not anaemia induced. Four days of treatment with aqueous extract of $J$. carnea leaves resulted in no significant increase $(\mathrm{p}>0.05)$ in WBC counts groups 3-5 rats when compared with group 2, though significantly lower than that of group 1 and 7. After 8 days' treatment with aqueous extract of $J$. carnea leaves, groups 3 and 6 showed no significant ( $>0.05$ ) decrease in WBC counts when compared with group 1 but significantly higher than WBC counts group 2. Also groups 4 and 5 rats showed no significant $(p>0.05)$ decrease in WBC counts when compared with group 2 while there was no significant $(\mathrm{p}>0.05)$ difference between WBC counts of groups and 7 rats.

Alanine transaminase activities of normal and anaemia induced male Wistar albino rats in Figure 5 showed significant $(\mathrm{p}<0.05)$ increase in ALT activity of group 2 anaemia induced untreated rats when compared with normal control (Group 1). Groups 3 and 4 anaemia induced rats treated with standard (Astyfer) and low dose of aqueous extract of $J$. carnea leaves respectively showed no significant $(\mathrm{p}>0.05)$ increase in ALT activities when compared with normal control. However, groups 5-6 anaemia induced rats and group 7 non-anaemia induced rats treated with 
high doses of aqueous extract of $J$. carnea leaves showed no significant $(\mathrm{p}>0.05)$ decrease in ALT activity when compared with normal control.

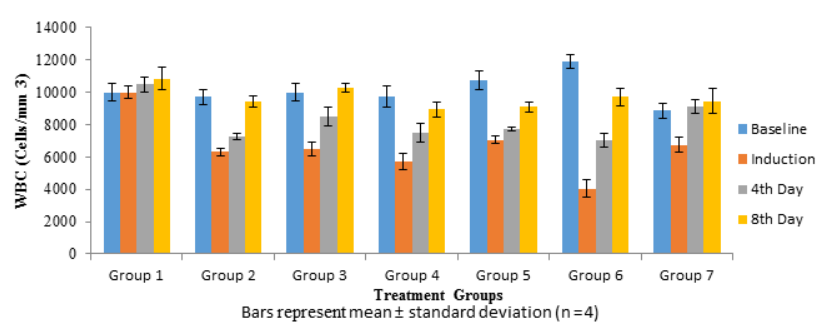

Figure 4. Effect of the aqueous extract of $J$. carnea leaves on the White Blood Cell (WBC) counts of male Wistar male rats before and after induction of anaemia.

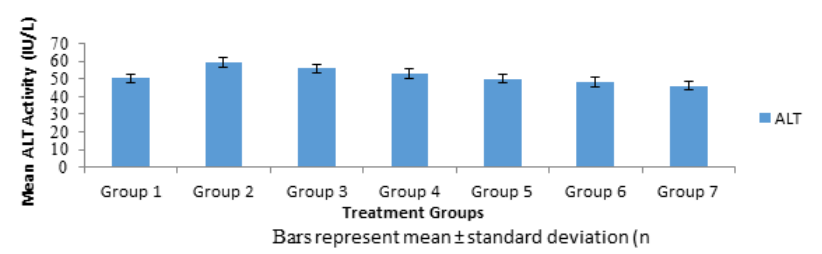

Figure 5. Effect of aqueous extract of J. carnea leaves on Alanine Transaminase (ALT) of anaemia induced male Wistar albino rats.

Aspartate transaminase activities of normal and anaemia induced male Wistar albino rats treated with aqueous extract of $J$. carnea leaves for $14 \mathrm{~d}$ shown in Figure 6 indicated no significant $(\mathrm{p}>0.05)$ increase in AST activity of group 2 anaemia induced not treated when compared with group 1. In like manner, there was no significant $(p>0.05)$ increase in AST activities observed in groups 4-6 anaemia induced treated rats with graded doses of aqueous extract of $J$. carnea leaves and group 7 that was not anaemia induced but received high dose of the extract for $14 \mathrm{~d}$ when compared with group 1. Group 2 rats that was anaemia induced not treated and group 3 rats that was anaemia induced, treated with standard drug (Astyfer) had highest and lowest AST activity respectively among all the groups tested.

The data in Figure 7 represent Alkaline Phosphatase (ALP) activities of normal and anaemia induced male Wistar albino rats. A significant $(\mathrm{p}<0.05)$ decrease in ALP activity was observed in group 2 rats when compared with normal control (group 1). In addition, all the anaemia induced rats treated standard drug (group 3) and aqueous extract of $J$. carnea leaves (groups 4-6) showed no significant $(\mathrm{p}>0.05)$ decrease in ALP activities when compared with normal control. In like manner, group 7 non-anaemia induced rats treated with high dose of the aqueous extract showed $\mathrm{n}$ significant decrease in ALP activity relative to group 1 .

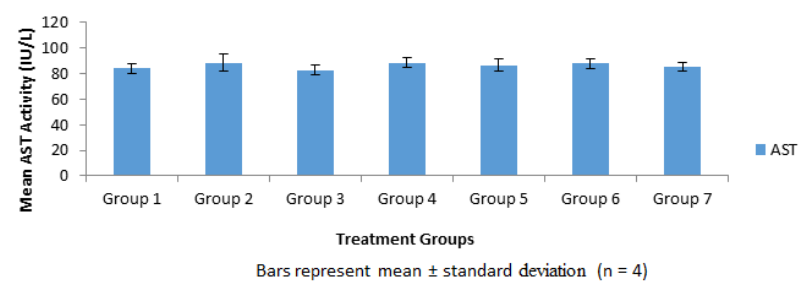

Figure 6. Effect of aqueous extract of J. carnea leaves on Aspartate Transaminase (AST) activity of anaemia induced male Wistar albino rats.

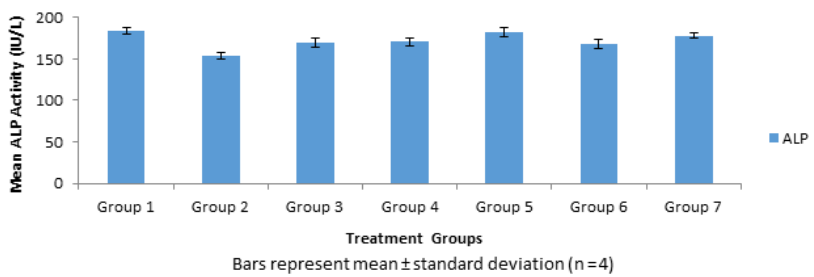

Figure 7. Effect of aqueous extract of J. carnea leaves on the Alkaline Phosphatase (ALP) activities of anaemia induced male Wistar albino rats.

Results in Figure 8 showed serum urea concentration of normal and anaemia induced male Wistar albino rats. Group 1 (normal control) that received on normal saline show low urea concentration while no significant $(p>0.05)$ increase in urea concentration was observed in-group 7 (normal rats) that received high dose of $J$. carnea leaves when compared with the group 1. It was observed that untreated anaemia induced group 2 , standard drug treated anaemia induced group 3 and groups 4-6 anaemia induced rats treated with aqueous extracts of $J$. carnea leaves respectively showed no significant increase $(p>0.05)$ in the urea concentrations when compared with the normal group (group 1).

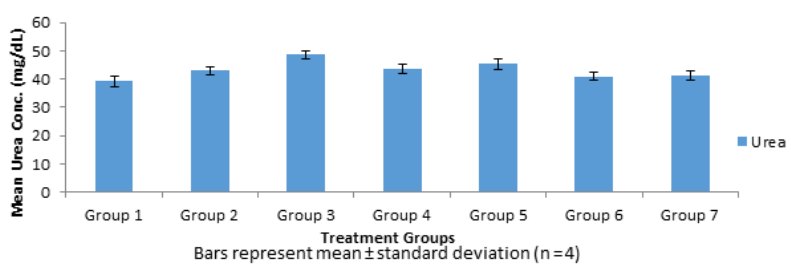

Figure 8. Effect of the aqueous extract of J. carnea leaves on the urea concentrations of anaemia induced male Wistar albino rats.

The data in Figure 9 shows serum creatinine levels in normal and anaemia induced male Wistar albino rats with no significant $(p>0.05)$ increase observed in the creatinine concentration of all anaemic rat when compared with the normal control (group 1). However, no significant decrease ( $p>0.05)$ was observed in creatinine concentration in-group 7 when compared with the normal control (group 1). 


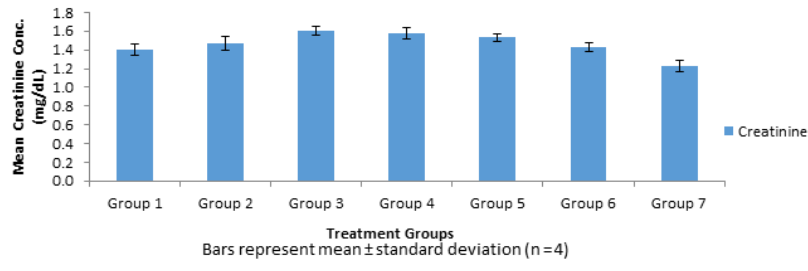

Figure 9. Effect of the aqueous extract of Justicia carnea leaves on creatinine concentration of anaemia induced male Wistar albino rats.

\section{Discussion}

Many foods of plants origin have been shown to be rich in numerous health benefits attributed to their nutraceutical properties [7]. Green leafy vegetables are particularly important in promoting good health because of their nutritive contents and pharmacological activities exhibited by their numerous phytochemicals [27]. In this study, nutritive potentials and effects of aqueous extract of Justicia carnea leaves on biochemical indices of anaemic male Wistar albino rats were investigated.

Proximate analysis of the aqueous extract of $J$. carnea leaves showed that it contains appreciable amounts of $53.07 \pm 0.07 \%$ carbohydrate, $9.26 \pm 0.02 \%$ ash, and $26.71 \pm 0.02 \%$ protein. The result of proximate composition obtained in this study showed a deviation from the findings Faiza et al. who reported that the leaves contain $54 \%$ carbohydrate, $11.62 \%$ ash, and $21.33 \%$ protein [14]. The difference could be attributed to environmental factors prevailing during the plant growth or time of collection and processing [28]. Carbohydrate is in appreciable quantity showing that it can be a good source of energy. Ash consists of inorganic matters such as minerals (calcium, potassium, mercury, zinc). The presence of high ash content suggests richness of the plant extract in mineral contents that could help in maintenance of electrolytes balance and enzyme functions possibly as cofactors.

The high levels of phytochemical constituents observed in this study indicate richness of aqueous extract of $J$. carnea leaves in important pharmacologically active bio-constituents that could promote quality human healthy. Flavonoids are the largest group of plant phenols, provide much of flavour, and colour to fruits and vegetables [29]. This may be attributed to the strong flavour and deep red colour despite the greenish nature of $J$. carnea leaves when boiled for consumption. Flavonoids and phenols constitute a wide range of substances that play important roles in protecting biological systems, serve as potent water-soluble antioxidants and free radical scavengers that prevent oxidative cell damage, lower the risk of heart diseases and have strong anticancer activity [30]. Consumption of flavonoids rich foods like aqueous extract of $J$. carnea leaves in right proportions reduces risks of diseases and medical conditions caused by excess oxidative stress. This health benefit of flavonoids is attributed to its antioxidant activity [31]. Hence, aqueous extract of $J$. carnea leaves possess some bioactive compounds that could serve as potential source of drugs and preventive measures against oxidative damage when ingested by animals in right quantities. Plant extracts rich in alkaloid possess pharmacological activities and are used as antibacterial, antifungal, dyes, spices, local anaesthetic, anti-hypertensive, anti-malarial activity, antiarrhythmic, anti-cancer, and as stimulant most especially cocaine, which have variety of toxic effects on animals [32]. The moderate saponins level observed in this aqueous extract could lower serum cholesterol levels in animals when the plant leaves are consumed in right proportion [33]. High phenols content present this plant aqueous extract suggest that consumption of adequate amount of this plant leaves could confer significant health benefits such as stimulation of bile secretion, reduction of blood cholesterol and modulate lipid levels in addition to antimicrobial activity [32]. Tannins when present large amount act as anti-nutrients and interfere with iron absorption by forming complex with iron in the gastrointestinal lumen that reduces bioavailability of iron [34]. High levels of tannins in plants also decrease activity of digestive enzymes such as $\alpha$-amylase, trypsin, chymotrysin and lipase and may cause damage to the mucosa of digestive tract and reduce the absorption of nutrients such as vitamin B12 [35]. Low tannins found in this plant extract is an indicative that iron absorption cannot be impaired by the tannin, thus the iron content in this extract and other dietary sources are available for uptake and utilization.

The low levels of antinutritional factors such as phytate, trypsin inhibitor, oxalate, hydrogen cyanide, and haemagglutinin contents observed in the aqueous extract of $J$. carnea leaves indicate that they may not able to impair nutrient availability and digestibility. Most antinutritional factors have been shown to exert positive effects when taken in low concentrations. Thus, low antinutritional factors in this plant extract could be responsible for some of its observed nutraceutical properties. For instance, diabetic patients are encouraged t consume foods of plant origin that contain little amount of phytate to reduce glucose absorption and prevent oxidative stress commonly experienced in uncontrolled diabetes. This is attributed to the ability of phytate to inhibit alpha amylase activity and xanthine oxidase activity respectively.

The high levels of minerals and vitamins observed in this study indicate leaves of $J$. carnea could serve as good source of vitamins and minerals [14]. This is in agreement with our result here. Leaves extract of $J$. carnea are shown to be a rich source of B2, B12, B9 and B1. The riboflavin content of $J$. carnea $(2.50 \pm 0.50 \mathrm{mg} / \mathrm{g})$ was higher when compared with similar plant like $T$. occidentalis $(0.45 \mathrm{mg})$. B vitamins play vital role in the function of the nervous system, aid in the formation of red blood cells and help to build tissues [36]. Vitamins such as vitamins $\mathrm{C}, \mathrm{E}$ and $\mathrm{A}$ are antioxidants that could scavenge excess endogenous and exogenous free radicals present suggesting their possible role in curbing the incidence of oxidative stress in humans and animals. In the same manner, vitamin $C$ is suggested in managing common cold [14]. Green leafy vegetables and fruits are established dietary sources of vitamin C. Vitamin C is also vital in the body as it chelates with iron to enhance iron absorption [37]. The leaves are rich 
in iron and calcium that play significant physiological function in oxygen transport through haemoglobin formation and borne mineralization respectively. Some anti-oxidant enzymes require metal ions for their activity [38].

The result obtained from the acute toxicity $\left(\mathrm{LD}_{50}\right)$ study of the aqueous extract of $J$. carnea leaves indicated the aqueous extract possesses no toxic effects as no death or adverse reactions were observed in the mice that administered low to high doses of the aqueous extract after $24 \mathrm{~h}$ of administration. This suggests high tolerance and safety level of the aqueous extract that could be attributed to the extract lacking toxic constituents that could trigger adverse reactions at tested doses. It also implies that the leaves are relatively safe for human and animal consumptions but excessive consumption of the aqueous extract could be chronically toxic as nothing is completely safe.

The high percentage Packed Cell Volume (PCV), haemoglobin concentrations $(\mathrm{Hb})$ and Red Blood Cell (RBC) counts baselines observed in this study showed that all the male Wistar albino rats used in this study were normal and free from anaemia prior to anaemia induction. However, significant decrease in $\mathrm{PCV}, \mathrm{Hb}$, and $\mathrm{RBC}$ observed in groups 2-6 rats following anaemia induction could be a confirmation that these groups of rats had suffered anaemia. The significant increase in PCV and RBC counts observed in-group 3 and groups 4-6 rats after 4 days of treatment with standard drug (Astyfer) and aqueous extract of $J$. carnea leaves could be attributed to blood boosting effects of the standard and the extract respectively. The extract may be rich in bioactive constituents promote activities of haematopoietic cells leading to production of more blood cells in addition to stabilization of blood in circulation. Aqueous extract of $J$. carnea leaves possess blood boosting activity similar to Astyfer (standard drug) as there were no significant difference observed between haematological indices of group 3 anaemic rats treated Astyfer and groups 4-6 anaemic rats treated with graded doses of aqueous extract of $J$. carnea leaves. The increased $\mathrm{PCV}, \mathrm{Hb}$, and $\mathrm{RBC}$ counts observed in group 2 rats after 8 days of treatment could be attributed to the recovery of rats from anaemic conduction as more blood cells produced since haematopoietic cells were affected by anaemia induction. These suggest that these anaemia-induced rats through blood withdrawal could recover from anaemia without treatment but require longer time to be achieved. The initial increase in the WBC count could be because of anaemia that was induced in the animals. The animals' immune system may have assumed the cause of anaemia could to be because of infection or disease and hence increase the production of white blood cells to fight such infections [39]. It has been known that WBC counts increase rapidly following pathogens evasion of the body system and the system's normal physiological response will be to boost the body defence mechanisms [40]. The loss of blood due to anaemia probably could be seen by the animal's body defence mechanism because of an underlying disease or infection and so produce more of the WBC to fight such infection or disease. After the $8^{\text {th }}$ day of treatment, it was observed that the white blood cell count increased, though not significant probably because the system has recognized that the actual cause of anaemia was not due to infection or disease. The slight increase observed in all the haematological parameters of group 2 (positive control) rats could be attributed to changes associated with erythropoietic response in the peripheral blood in the animals during the first four days after induction of anaemia [41].

The standard drug contains among other things, active components such as iron, folic acid and vitamin B12 that have been reported to restore blood components. The extract could possibly restore blood components through the same mechanism as the standard drug. In addition, it has been reported that the leaves of $J$. carnea contain high quantity of iron $(204.0 \mu \mathrm{g} / \mathrm{g})$ and calcium $(5.15 \%)$ [14]. In like manner, the aqueous extract of $J$. carnea leaves used in this contains appreciable levels of B vitamins such as B1, B2, B6, B12 and iron that could have worked synergistically toward recovery aqueous extract of $J$. carnea leaves treated anaemic rats from their anaemic conditions. Antioxidants phytochemicals like flavonoids and antioxidant vitamins (A, C, and E) helps in recovery from anaemia mostly by stabilizing blood cells. The leaves could be said to be beneficial in the treatment of anaemia that is characterized by a decrease in erythrocyte number. The aqueous extract may be rich in pharmacologically active constituents that could replenish blood cells and other haematologically parameters possibly by haematopoietic stimulation mechanism. It contains many nutrients that could be utilized to boost blood counts. For instance, the high level of iron found in this aqueous extract could help in increasing haemoglobin concentrations through increased rate of heam formation [39].

Ogugua et al. reported that significant increase in the activities of serum liver marker enzymes such as Alanine Amino Transferase (ALT), Aspartate Amino Transferase (AST), and alkaline phospahaase serve as indicators of liver damage most especially increase in ALT activity [42]. Contrary to their findings, there were no significant decrease in liver marker enzymes activities observed in this study indicating that the aqueous extract $J$. carnea leaves have relatively no toxic effects on liver functions. High levels of phenols and flavonoids found in this aqueous extract could protect liver cells from adverse effects of reactive oxygen species/free radicals generated from leakages in electron transport chain and others from exogenous sources [43]. Thus, high contents of antioxidant vitamins and phytochemicals contained in the aqueous extract coupled with absences of any hepatotoxic effects observed in this study suggest that the extract could possess significant hepatotoxic effects and consumption of right quantity may promote health liver function.

In the renal function test of the animals, there was a slight increase in the urea concentration of the rats in the treated group especially groups 3 and 7 when compared with the normal group, though this increase was not significant in any of the groups. Urea is dependent on protein intake and some other factors, hence, the increase could be attributed to the amino acid content of the drug that is rich in glycine, lysine 
and histidine. The increase in serum creatinine level observed in-group 7 administered equivalent dosages with group 5 could be as a result of changes in physiological condition of the animals and may not be as a result of damage since the increase was not observed in group 5 that took same dosage. In assessing the renal function, urea concentration is dependent on some parameters, so creatinine is more reliable since its rate of production is constant and rate of excretion is dependent on muscle mass of the animal involved. In view of this, the decrease in the concentration of creatinine in the group with the highest dosage of the induced animals is an indication that the plant extract does not have toxic effect on renal function, and could subsequently not affect erythropoietin production. Therefore, liver and kidney function tests showed no toxicity in the rats after the 14 days of treatment.

\section{Conclusion}

The findings of this study indicate that the aqueous extract of $J$. carnea leaves is rich in nutritive components with trace amount of antinutitional factors. It possesses blood boosting and replenishing properties that enabled it effectively restored blood levels of anaemic rats to normalcy within every short period of treatment. The aqueous extract is relatively safe for consumption, as it caused no acute toxicity, hepatotoxicity and renal toxicity in the animals that consumed it. These findings validate claims by local consumers that it possesses antianaemic effects that boost blood levels in anaemic patients, pregnant women and replenishes blood lost through menstrual cycle when consumed in adequate amount.

\section{Conflict of Interest}

Authors declare no conflict of interest.

\section{References}

1. World Health Organization (WHO). The World Health Report 2002: Reducing risks, promoting healthy life. Geneva WHO 2002.

2. McEvoy MT. Anaemia, bleeding, and blood transfusion in the intensive care unit: Causes, risks, costs, and new strategies. Am J Crit Care 2013; 22: 1-13.

3. Weiss G, Goodnough L. Anaemia of chronic disease. N Engl J Med 2005; 352: 1011-1023.

4. Grewal A. Anaemia and pregnancy: anaesthetic implications. Ind J Anaesth 2010; 54: 380-386.

5. Hoffbrand AV, Moss PAH, Pettit JE. Essential haematology (5th Edn.). Blackwell Publishing, Oxford 2006; 1-108.

6. Rosdahl CB, Kowalski MT. Textbook of nursing. Lippincott Williams and Wilkins, New York 2008; 12-20.

7. Hunter KJ, Fletcher JM. The antioxidant activity and composition of fresh, frozen, jarred and canned vegetable. Innov Food Sci Emerg Technol 2002; 3: 399-406.

8. Alada ARA. The haematological effect of Telfelria occidentalis diet preparation. Afr J Biomed Res 2000; 3: 185-186.
9. Dina OA, Adedapo AA, Oyinloye OP, Saba AB. Effect of telfairia occidentalis extract on experimentally induced anaemia in romestic Rabbits. Afr J Biomed Res 2006; 3: 181-183.

10. Correa GM. Chemical constituents and biological activities of species of Justicia: A review. Braz J Pharmacogn 2012; 22: 220-238.

11. Wasshausen DC, Wood JR. Acanthaceae of Bolivia. Contributions from the US National Herbarium 2004; 49: 151-152.

12. Parker JL, Pearson B. New plant records from the big island for 2010-2011. Records of the Hawaii biological survey for 2011. Part II: Plants. Bishop Museum Occasional Papers 2012; 113: 65-74.

13. Uroko RI, Egba SI, Achi NK, Uchenna ON, Agbafor A, Ngwu OR, Nweje-Anyalowu PC, Ogbonna CE. Research article effects of aqueous extracts of palm fruits (Elaeis guineensis) on liver function indices of male Wistar albino rats. Res J Med Plants 2017; 11: 148-159.

14. Faiza R, Waqas KK, Adeel M, Muhammad G. Detection of bioactive fractions of Justicia adhatoda leaves. Canadian J Appl Sci 2013; 1: 388-398.

15. AOAC. Official methods of analysis (15th Edn.). Washington D.C. Association of Official Analytical Chemist 1990; 69-88.

16. Harborne JB. Phytochemical methods. A guide to modern technology of plant analysis (3rd Edn.). Chapman and Hall New York 1998; 88-185.

17. Trease GE, Evans MC. Textbook of pharmacognosy (13th Edn.). Bailiere Tindall 1983; 700-775.

18. Pearson DA. Chemical analysis of foods (9th Edn.). Church-hill Livingstone Edinburgh London 1976; 196-514.

19. APHA. Standard methods for examination of water and waste water (19th Edn.). American Public Health Association, American Water Works Association and Water Pollution Control Federation, Washington, D.C 1998.

20. Stone SH. Method of obtaining venous blood from the orbital sinus of rats or mouse. Science 1954; 119: 100-102.

21. Lorke D. Determination of acute toxicity. Arc Toxicol 1983; 53: 275-279.

22. Dacie JV, Lewis SM. Practical haematology (7th Edn.). Churchhill Livingstone Edingburgh 1991; 535-544.

23. Wroblewski F, Ladue JS. Serum glutamic pyruvic transaminase in cardiac with hepatic disease. Proc Soc Exp Biol Med 1956; 9: 569-571.

24. International Federation of Clinical Chemistry (IFCC). Method for determination of alkaline phosphatase. J Clin Chem Clin Biochem 1983; 21: 731-748.

25. Varley H, Alan HG. Tests in renal disease. William Heinmann Medical Book Ltd; London Pract Clin Biochem 1984; 1123: 10 . 
26. Peters $\mathrm{JH}$. The determination of creatinine and creatinine in blood and urine with the photoelectric colorimeter. J Biol Chem 1942; 146: 179-186.

27. IBM Corporation. IBM SPSS Statistics for Windows, Version 20.0. Armonk, NY: IBM Corp. 2011.

28. Gupta S, Prakash J. Studies on Indian green leafy vegetables for their antioxidant activity. Plant Foods Human Nutrition 2009; 64: 39-45.

29. Amadi BA, Ibegbulem CO, Egbebu AC. Assessment of the effect of aqueous extract of (Asimina triloba) root on organ weights and liver function of albino rats. Int $\mathrm{J}$ Nat Appl Sci 2006; 2: 79-81.

30. Tanwar B, Ranji M. Flavonoids: dietary occurrence and health benefits. J Compl Med Drug Discov 2012; 2: 59-68

31. Okwu DE. Phytochemical and vitamin content of indigenous spices of South Eastern Nigeria. J Sustain Agr Env 2004; 6: 30-34.

32. Uroko RI, Sangodare RSA, Muhammad KH, Asadu CL. Effect of methanol extract of Abrus precatorius leaves on male Wistar albino rats induced liver damage using carbon tetrachloride (CCl4). J Biol Sci 2015; 15: 116-123.

33. Mamta S, Jyoti S, Rajeev N, Dharmendra S, Abhishek G. Phytochemistry of medicinal plants. J Pharmacogn Phytochem 2013; 1: 168-182.

34. Matsuura M. Saponins in garlic as modifiers of the risk of cardiovascular disease. J Nutr 2001; 131: 1000-1005.

35. Praveen KA, Kumud U. Tannins are astringent. J Pharmacogn Phytochem 2012; 1: 45-50.

36. Doss A, Pugalenthi M, Valivel VG, Subhashini G, Anitha SR. Effects of processing technique on the nutritional composition and antinutrients content of under-utilized food legume Canavalia ensiformis LDC. Int Food Res J 2011; 18: 965-970.
37. Zingg JM, Azzi A, Myedani M. Genetic polymorphisms as determinates for disease-preventive effects of vitamin E. Nutr Rev 2008; 66: 406-410.

38. Salovaara S, Sandberg AS, Andlid T. Organic acids influence iron uptake in the human epithelial cell line caco-2. J Agr Food Chem 2002; 50: 6233-6238.

39. Stover PJ, Caudill MA. Generic and epigenetic contributions to human nutrition and health: Managing genome-diet interactions. J Am Diet Assoc 2008; 108: 1480-1485.

40. Eyong EU, Umoh IB, Ebong PE, Eteng MU, Antai AB, Akpa AO. Haematoxic effects following ingestion of Nigerian crude oil and crude oil polluted shellfish by rats. Niger J Physiol Sci 2004; 19: 1-6.

41. Okonkwo CC, Njoku UO, Mbah AM. Anti-anaemic effect of methanol seed extract of Sphenostylis stenocarpa (African yam bean) in Wistar albino rats. Afr J Pharm Pharmacol 2013; 7: 2907-2913.

42. Hillman RS, Finch CA. Redell manual (4th Edn.). FA Davis Company, Philadelphia. 1974; 24-26.

43. Ogugua VN, Uroko RI, Egba SI, Agu O. Hepatoprotective and healthy kidney promoting potentials of methanol extract of Nauclea latifolia in alloxan induced diabetic male Wistar Albino rats. Asian JBiochem 2017; 12: 71-78.

\section{*Correspondence to}

Uroko Robert Ikechukwu

Department of Biochemistry

College of Natural Sciences

Michael Okpara University of Agriculture

Nigeria 